\title{
PERÍODOS DE INTERFERÊNCIA DE PLANTAS DANINHAS EM GENÓTIPOS DE BATATA-DOCE
}

\author{
Jair Tenório Cavalcante ${ }^{1 *}$, Paulo Vanderlei Ferreira ${ }^{2}$, Jorge Luiz Xavier Lins Cunha ${ }^{3}$, \\ Antônio Barbosa da Silva Júnior ${ }^{4}$, Moisés Tiodoso da Silva ${ }^{5}$, Islan Diego Espindula de \\ Carvalho ${ }^{6}$
}

${ }^{1}$ Professor Doutor da Universidade Federal de Alagoas, Proteção de Plantas, Rio Largo (AL). *Email: jairtc@ig.com.br

${ }_{2}^{2}$ Professor Doutor da Universidade Federal de Alagoas, Melhoramento Genético de Plantas, Rio Largo (AL).

${ }^{3}$ Eng $^{\mathrm{o}}$. Agrônomo, Doutor da Universidade Federal de Alagoas, Manejo de Plantas Daninhas, Rio Largo (AL).

${ }^{4}$ Doutorando da Universidade Federal de Alagoas, Proteção de Plantas, Rio Largo, Rio Largo (AL).

${ }^{5}$ Mestrando na Universidade Federal de Alagoas, Produção Vegetal, Rio Largo (AL).

${ }^{6}$ Doutorando na Universidade Federal Rural de Pernambuco, Melhoramento Genético de Plantas, Recife (PE).

RESUMO: O cultivo da batata-doce, mais precisamente no Nordeste brasileiro, apresenta rendimentos abaixo do seu potencial produtivo, devido principalmente à utilização de variedades locais não melhoradas e manejo inadequado de plantas daninhas. Diante destes fatos, implantou-se um experimento em Rio Largo - Alagoas, no ano de 2013, objetivando determinar o período crítico de prevenção à interferência (PCPI) de plantas daninhas em três genótipos de batata-doce, sendo os Clones 6 e 14, desenvolvidos pelo SMGP/CECA/UFAL e a variedade Sergipana, bastante cultivada na região. O delineamento foi em blocos casualizados no fatorial 3 x 14, com três repetições; ficando três genótipos em 14 períodos de interferência, distribuídos em sete períodos de controle, a partir dos quais as plantas daninhas eram controladas e sete períodos de convivência, a partir dos quais as plantas daninhas não eram mais controladas $(0,10,20,30,40,50$ e 60 DAP). As plantas daninhas foram identificadas e avaliadas através dos parâmetros fitossociológicos: densidade e massa seca total. Nos genótipos de batata-doce foram avaliadas as variáveis: número de raízes comerciais, massa média de raízes comerciais e rendimento de raízes tuberosas comerciais. As espécies predominantes foram: Richardia grandiflora Cham. \& Schltdl., Ageratum conyzoides L. e Eleusine indica (L.) Gaertn. A ausência de controle reduziu em 53,5\%, 65\% e $69,3 \%$ a produtividade do Clone 6, da variedade Sergipana e do Clone 14, respectivamente. O PCPI foi dos 23 aos 42 DAP, dos 24 aos 46 DAP e dos 17 aos 40 DAP, para a variedade Sergipana, o Clone 6 e o Clone 14, respectivamente.

Palavras-chave: Ipomoea batatas (L.) Lam. Competição. Época de controle.

\section{PERIODS OF WEED INTERFERENCE IN SWEET POTATOES GENOTYPES}

ABSTRACT: The cultivation of sweet potatoes, more precisely in the Brazilian Northeast, has income below its productive potential, mainly due to the use of unimproved local varieties and inadequate weed management. Given these facts, an experiment was conducted in Rio Largo - Alagoas in 2013, aiming to determine the critical period of interference prevention (PCPI) weed in three sweet potato genotypes, and the Clones 6 and Cultura Agronômica, Ilha Solteira, v.26, n.4, p.640-656, 2017 
14, developed by SMGP/CECA/UFAL and Sergipana variety, largely grown in the region. The design was randomized blocks in factorial 3 x 14 with three replications; getting three genotypes in 14 periods of control, over seven periods of control, from which weeds were controlled and seven periods of coexistence, from which weeds were not controlled $(0,10$, 20, 30 , 40, 50 and 60 DAP). The weeds have been identified and evaluated through the phytosociological parameters: density and total dry mass. The sweet potato genotypes using the variables: number of commercial roots, average weight of commercial roots and yield of commercial tuberous roots. The species Richardia grandiflora Cham. \& Schltdl., Ageratum conyzoides L. and Eleusine indica (L.) Gaertn. they were predominant. And the interference reduced by $53.5 \%, 69.3 \%$ and $65 \%$ the productivity of Clone 6, the variety Sergipana and Clone 14, respectively. The PCPI was from 23 to 42 DAP, from 24 to 46 DAP and 17 to 40 DAP, for Sergipana variety, Clone 6 and Clone 14, respectively.

Key words: Ipomoea batatas (L.) Lam. Competition. Control season.

\section{INTRODUÇÃO}

A batata-doce (Ipomoea batatas (L.) Lam.) é uma cultura de grande importância para diversas regiões do planeta, contribuindo para a subsistência de diversos povos. Atualmente segundo a FAO (2014), a produção mundial é de 106.601 .602 toneladas, desse montante $74,3 \%$ são produzidas na Ásia, 21,2\% na África, 3,6\% nas Américas e 0,8\% na Oceania. O país que apresenta maior destaque na produção é a China com 71.539 .950 toneladas, o Brasil no mesmo período apresentou produção de 525.814 toneladas.

A produtividade média de batata-doce no Brasil foi de 13,24 $\mathrm{t} \mathrm{ha}^{-1}$ no ano de 2014, baixa em comparação com a China que no mesmo período foi de 21,15 t ha-1 (IBGE, 2014). Os principais motivos dos baixos índices produtivos apresentado nas áreas cultivadas devese a baixa adoção de tecnologia agronômica no sistema produtivo, solos de baixa fertilidade, variedades pouco produtivas e/ou pouco adaptadas à região, competição com plantas daninhas, entre outros (CARDOSO et al., 2013).

A interferência de plantas daninhas em uma cultura é o efeito negativo ou não resultante da presença de determinadas comunidades infestantes no local de cultivo. $\mathrm{O}$ grau de interferência depende de diversos fatores, tais como composição, densidade, distribuição, espécie, variedade tanto das plantas infestantes como da espécie cultivada, além do período de convivência, condições do solo, clima e manejo. De maneira geral, pode-se dizer que, quanto maior for o período de convivência, maior será o grau de interferência (SOARES et al., 2010).

Geralmente, quanto menor o período de convivência entre cultura e plantas daninhas, menor será o grau de interferência. Contudo, uma infestação moderada de plantas daninhas poderá ser tão danosa à cultura quanto uma infestação com alta população, dependendo da época de seu estabelecimento, entre outros fatores. Esse fato justifica, portanto, o estudo da

Cultura Agronômica, Ilha Solteira, v.26, n.4, p.640-656, 2017 
época ideal de controle de plantas daninhas em cada cultura, visando o mínimo possível de redução na produtividade, mas sem prejudicar também o ambiente (SILVA; SILVA, 2009).

Existem poucas as informações acerca dos períodos de interferência das plantas daninhas sobre a cultura da batata-doce, especialmente quando se trata de avaliação de novos materiais. Segundo Seem et al. (2003), o período anterior a interferência é de 14 dias, o período total de prevenção a interferência é de 42 dias e o período crítico de prevenção a interferência situa-se entre 14 e 42 dias. Porém é sabido que as características morfológicas e fisiológicas de cada genótipo influenciam na interferência de plantas daninhas. Diante disso, o presente trabalho teve como objetivo observar se existem diferenças quanto ao período crítico de prevenção a interferência de plantas daninhas entre os três genótipos de batata-doce avaliados, determinando os períodos anterior, total e crítico de prevenção à interferência das plantas daninhas.

\section{MATERIAL E MÉTODOS}

O experimento foi desenvolvido em condições de campo na área experimental do Setor de Melhoramento Genético de Plantas do Centro de Ciências Agrárias da Universidade Federal de Alagoas (SMGP/CECA/UFAL), no ano de 2013, localizada no Campus Rio Largo, BR 104 Norte, km 85, Rio Largo - Alagoas. Foram avaliados três genótipos de batata-doce: dois Clones obtidos pelo SMGP, o Clone 06 e o Clone 14, e a variedade Sergipana, uma das mais cultivadas no Estado. Os dados meteorológicos coletados na Estação Agrometeorológica do CECA/UFAL - Rio Largo - AL, mostraram que à pluviosidade acumulada durante o ciclo da cultura foi de 990,2 $\mathrm{mm}$ e temperatura média de $23,68^{\circ} \mathrm{C}$, temperatura média da mínima de $20,1^{\circ} \mathrm{C}$ e temperatura média da máxima de $27^{\circ} \mathrm{C}$, expostos nos gráficos apresentados na Figura 1(A e B). A implantação do experimento foi realizada durante o período chuvoso, época de plantio mais usada pelos produtores de batata-doce na região.
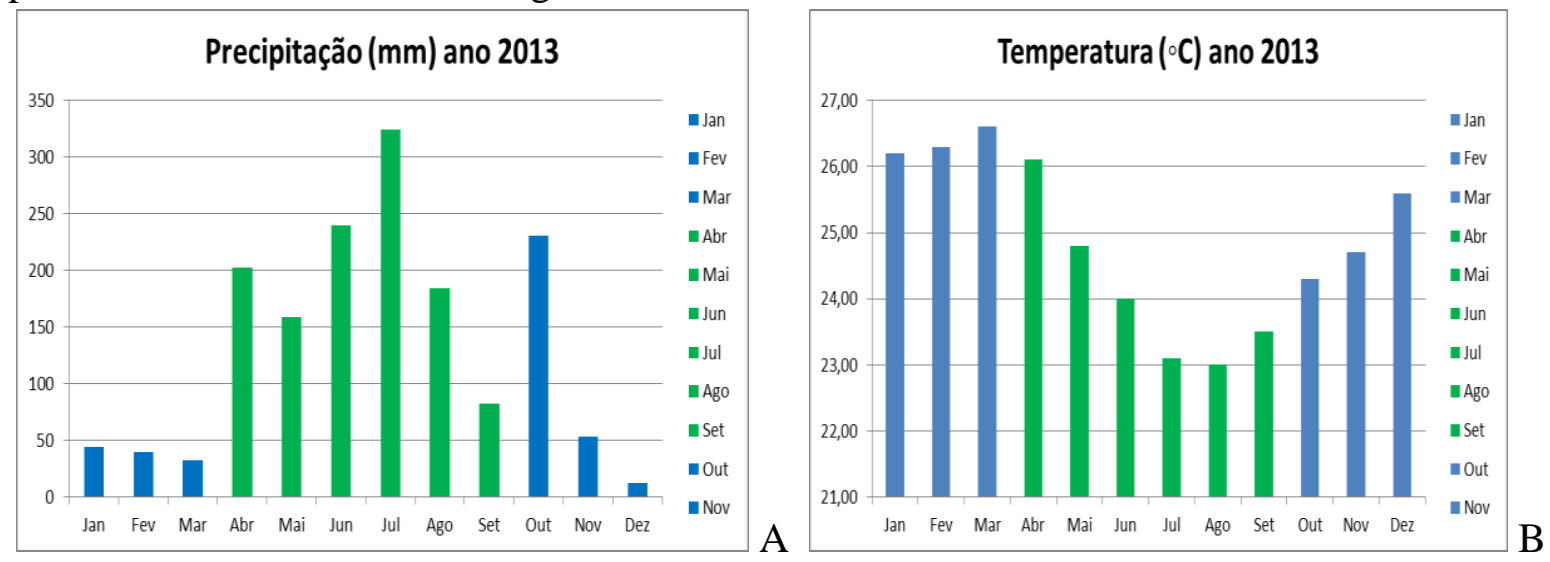

Figura 1. Precipitações (A) e Temperaturas média mensal do ar (B), durante a condução do experimento. Rio Largo - AL CECA/UFAL, 2013.

Cultura Agronômica, Ilha Solteira, v.26, n.4, p.640-656, 2017 
O delineamento utilizado foi em blocos casualizados em um fatorial 3 x 14, com três repetições, sendo, três genótipos de batata-doce e 14 períodos de interferências. Os períodos de interferências foram: sete períodos de controle, a partir dos quais as plantas daninhas eram controladas $(0,10,20,30,40,50$ e 60 dias após o plantio - DAP) e sete períodos de convivência, onde as espécies infestantes emergidas após esses intervalos não eram mais controladas $(0,10,20,30,40,50$ e 60 - DAP). Os períodos de controle e de convivência foram realizados com intervalos de dez dias, considerando como testemunha infestada e livre de infestação durante todo o ciclo. Cada parcela continha quatro leiras de 5,0 m de comprimento com 0,30 m de altura, com 12 plantas por leira, espaçadas de 0,80 x 0,40 m, tendo como área útil às duas leiras centrais.

O solo foi preparado com uma aração e duas gradagens cruzadas; as leiras foram construídas com sulcador; a adubação mineral em fundação foi aplicada de acordo com as recomendações das análises do solo (Central Analítica ${ }^{\circledR}$ ), através do método da EMBRAPA

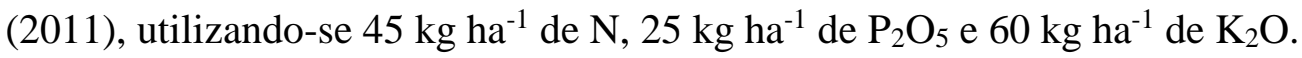

O controle das plantas daninhas foi realizado no final de cada período de convivência e nos períodos de controle, por meio de capinas manuais e com o uso de enxada, de acordo com os tratamentos.

A comunidade de plantas daninhas foi avaliada durante o ciclo dos genótipos de batata-doce. Na coleta foi utilizado um quadrado vazado de metal com 0,25 $\mathrm{m}^{2}$, lançado de forma aleatória na área útil de cada parcela, onde as plantas foram interseccionadas rente ao solo, identificadas quanto à família, espécie e nome vulgar, quantificadas e levadas à estufa de circulação forçada de ar a $65^{\circ} \mathrm{C}$, até obtenção da massa constante. A caracterização da comunidade infestante foi realizada segundo a recomendação de Cunha et al. (2015), enquanto que o levantamento fitossociológico, calculando-se a densidade, a massa seca total e o índice de valor de importância (IVI) das plantas daninhas, foi realizado segundo Mueller-Dombois e Ellemberg (1974):

A colheita das raízes tuberosas foi realizada aos 130 DAP, avaliando-se: número de raízes comerciais (NRC), massa média das raízes comerciais (MMRC) e rendimento de raízes comerciais (RRC).

Os índices fitossociológicos referentes às plantas daninhas foram apresentados de forma descritiva. Os dados dos componentes de produção dos genótipos de batata-doce foram analisados separadamente em cada grupo (períodos de controle e de convivência com plantas daninhas), e submetidos a Analise de Variância e as médias comparadas pelo teste de Tukey, ao nível de 5\% de significância. Os rendimentos de raízes tuberosas comerciais foram submetidos à análise regressiva e adaptadas ao modelo não-linear Sigmoidal de Boltzman, utilizando programas estatísticos, conforme Kuva et al. (2003). 


\section{RESULTADOS E DISCUSSÃO}

\section{Avaliação dos caracteres relacionados às plantas daninhas}

A comunidade infestante foi composta por 26 espécies, em 14 famílias, sendo: Poaceae e Asteraceae, com quatro espécies, Fabaceae, Solonaceae, Cyparaceae, Euphorbiaceae, com duas espécies e as demais: Amarantaceae, Brassicaceae, Convovulaceae, Phyllanthaceae, Molluginaceae, Rubiaceae, Turneraceae, Portulacaceae, Scrophulariaceae, e Boraginaceae com apenas uma espécie.

As espécies de plantas daninhas que se destacaram com relação à densidade total (Den), foram: poaia branca (Richardia brasiliensis Gomes), capim-pé-de-galinha (Eleusine indica (L.) Gaertn.), mentrasto (Ageratum conyzoides L.), mussambê (Cleome affinis DC.), tiririca-de-brejo (Cyperus iria L.), capim tapete (Mollugo verticillata L.), maria pretinha (Solanum americanum Mill.) e capim colchão (Digitária horizontalis Willd.).

As maiores densidades de plantas daninhas foram atingidas no período de 20 a 50 dias após o plantio (DAP) nas áreas das parcelas cultivadas com o Clone 6 e a variedade Sergipana e no período de 20 a 40 DAP nas áreas das parcelas com o Clone 14, sendo que a maior densidade foi atingida aos 30 dias na área com a variedade Sergipana com 741,33 plantas $\mathrm{m}^{-2}$, e no período de 20 a 30 dias nas parcelas com o Clone 6 com 644,00 e 622,67 plantas $\mathrm{m}^{-2}$ respectivamente, e no Clone $14 \mathrm{com} 680,00$ e 648,25 plantas $\mathrm{m}^{-2}$ respectivamente (Figura 2).

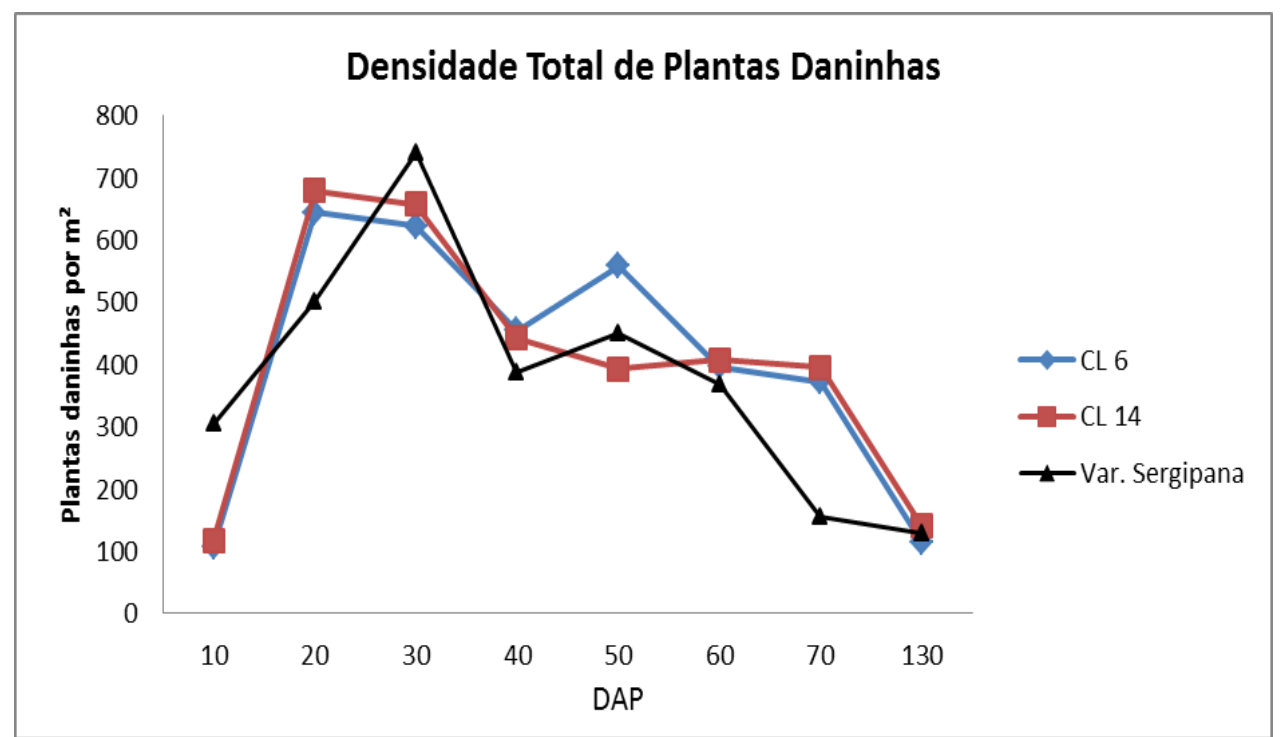

Figura 2. Densidade total das plantas daninhas infestantes (plantas $\mathrm{m}^{-2}$ ) em função dos períodos de convivência com genótipos de batata-doce. Rio Largo - AL, 2013.

As menores densidades de plantas daninhas ocorreram no período de 10 DAP, tanto para as áreas das parcelas com o Clone 6, com 106,67 plantas $\mathrm{m}^{-2}$, quanto para as áreas das parcelas com o Clone 14 com 117,33 plantas $\mathrm{m}^{-2}$, e no período de 130 DAP nas áreas das parcelas com a variedade Sergipana com 129,37 plantas $\mathrm{m}^{-2}$.

Cultura Agronômica, Ilha Solteira, v.26, n.4, p.640-656, 2017 
A partir dos 50 DAP, verificou-se redução na densidade populacional das plantas infestantes nas parcelas cultivadas com a variedade Sergipana e só aos 70 DAP nas parcelas cultivadas com os Clones 6 e 14. A baixa densidade de plantas infestantes permitiu o surgimento de novos indivíduos, que se desenvolveram, aumentando a massa seca das plantas daninhas, acumulada ao longo do ciclo da cultura. Costa et al. (2008), estudando a interferência de plantas daninhas na cultura da batata (Solanum tuberosum), verificaram que as maiores densidades de plantas daninhas foram a partir dos 14 DAP (249 plantas $\mathrm{m}^{-2}$ ) e aos 28 DAP (433 plantas $\mathrm{m}^{-2}$ ) para períodos de controle e convivência, respectivamente. E em outro ensaio, Costa et al. (2013), avaliando períodos de interferências das plantas daninhas na cultura da mandioca, verificaram que as maiores densidades das plantas daninhas foram atingidas aos 150 DAP $\left(50\right.$ plantas $\left.\mathrm{m}^{-2}\right)$ e aos 75 DAP (114 plantas $\left.\mathrm{m}^{-2}\right)$, para os períodos de controle e de convivência, respectivamente.

A massa seca total (MS) das plantas daninhas obteve comportamento crescente ao longo de todo o ciclo dos genótipos de batata-doce (Figura 3). Até os 30 DAP, observa-se um baixo acúmulo de massa seca. Após este período houve um acúmulo significativo, chegando ao final do ciclo, com valores de 778,69, 654,56 e 517,96 gramas $\mathrm{m}^{-2}$ nas áreas das parcelas cultivadas com o Clone 14, variedade Sergipana e o Clone 6, respectivamente.

Durante maior parte do ciclo dos genótipos de batata-doce, a massa seca das plantas daninhas foi semelhante, contudo, ao final, obtiveram valores diferenciados para os três genótipos.

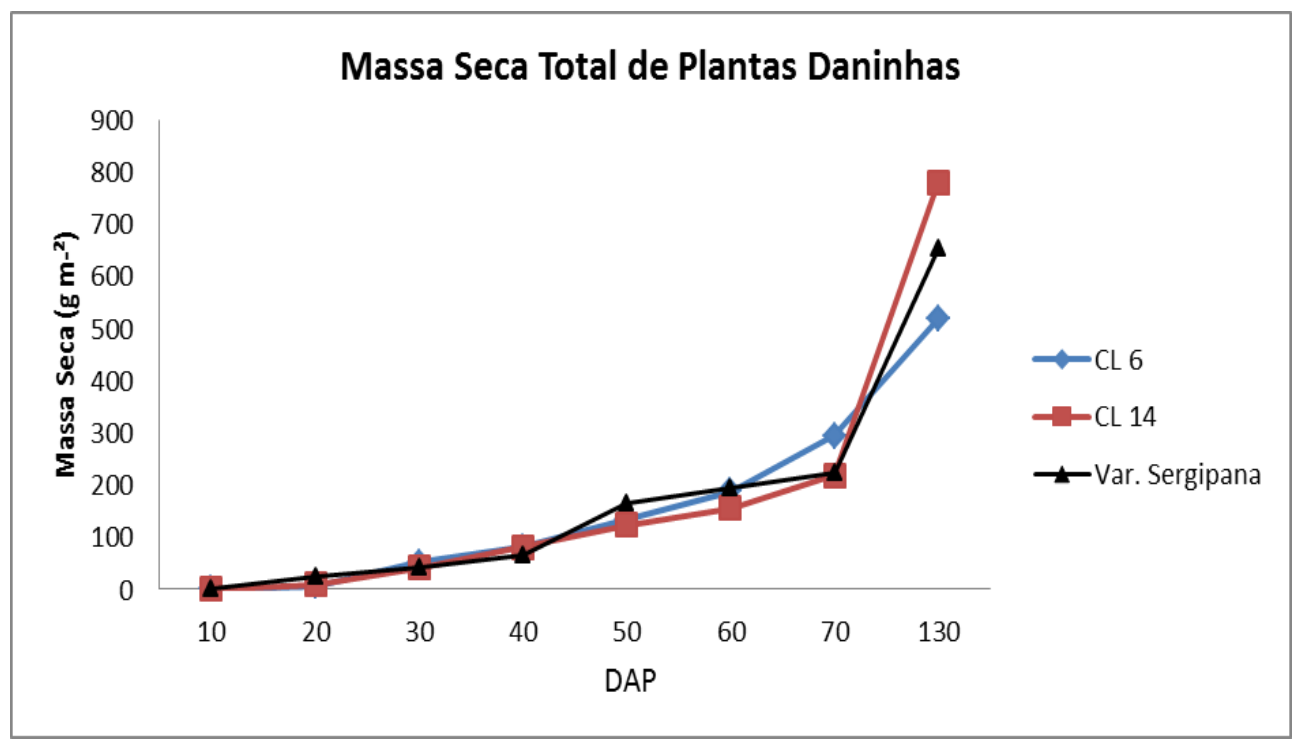

Figura 3. Massa seca total das plantas daninhas (gramas $\mathrm{m}^{-2}$ ) em função dos períodos de convivência com genótipos de batata-doce. Rio Largo - AL, 2013.

Freitas et al. (2004), avaliando períodos de interferência de plantas daninhas na cultura da mandioquinha-salsa, observaram um rápido incremento da biomassa total, aumentando rapidamente até 84 DAP; no período de 84 a 147 DAP ocorreu pequena queda na produção de biomassa, com rápido incremento a partir de 168 DAP até a última avaliação. Já Coelho et al. (2009), observaram que o acúmulo de massa seca das plantas Cultura Agronômica, Ilha Solteira, v.26, n.4, p.640-656, 2017 
daninhas na cultura da cenoura mostrou tendência crescente até 80 DAS $\left(2.439,45 \mathrm{~g} \mathrm{~m}^{-2}\right)$. O acúmulo total de massa seca pode ser considerado indicador mais confiável do que a população de plantas daninhas, no tocante ao grau de competição imposto à cultura (NEPOMUCENO et al., 2007).

\section{Avaliação dos caracteres relacionados às raízes tuberosas dos genótipos de batata- doce, em função dos períodos de controle das plantas daninhas}

Analisando o desdobramento de genótipos dentro dos períodos de controle de plantas daninhas, mostrados na Tabela 1, verificou-se para à variável rendimento de raízes comerciais (RRC), que quando os genótipos de batata-doce permaneceram durante todo o ciclo de cultivo na ausência da competição com as plantas daninhas, à variedade Sergipana apresentou maior rendimento, 29,23 $\mathrm{t} \mathrm{ha}^{-1}$, diferindo estatisticamente dos Clones 6 e 14, com rendimentos de 24,59 e 20,61 t ha-1 , respectivamente, que por sua vez diferiram entre si. A variedade Sergipana também apresentou rendimentos superiores aos dois Clones de batata-doce, nos tratamentos com controle das plantas daninhas a partir dos 10, 20 e 30 DAP; quando o controle foi realizado a partir dos 40 DAP, não houve diferença estatística entre os genótipos; e quando controle teve início a partir dos 50 e 60 DAP, o Clones 6 e a variedade Sergipana diferiram do Clone 14.

Tabela 1. Valores médios do rendimento de raízes comerciais (RRC), número de raízes comerciais (NRC) e massa média das raízes comerciais (MMRC), dos genótipos de batatadoce em função dos períodos de controle de plantas daninhas. Rio Largo-AL, CECA-UFAL, 2013

\begin{tabular}{lccccccc}
\hline Genótipos & \multicolumn{7}{c}{ Períodos de Controle (DAP) } \\
\cline { 2 - 8 } & $\mathbf{1 3 0}$ & $\mathbf{1 0 - 1 3 0}$ & $\mathbf{2 0 - 1 3 0}$ & $\mathbf{3 0 - 1 3 0}$ & $\mathbf{4 0 - 1 3 0}$ & $\mathbf{5 0 - 1 3 0}$ & $\mathbf{6 0 - 1 3 0}$ \\
\hline Sergipana & $29,23 \mathrm{a}$ & $28,77 \mathrm{a}$ & $26,13 \mathrm{a}$ & $23,49 \mathrm{a}$ & $21,12 \mathrm{a}$ & $16,42 \mathrm{a}$ & $10,11 \mathrm{ab}$ \\
Clone 6 & $24,59 \mathrm{~b}$ & $23,53 \mathrm{~b}$ & $22,55 \mathrm{~b}$ & $20,42 \mathrm{~b}$ & $19,08 \mathrm{a}$ & $17,14 \mathrm{a}$ & $12,29 \mathrm{a}$ \\
Clone 14 & $21,61 \mathrm{c}$ & $20,61 \mathrm{c}$ & $19,14 \mathrm{~b}$ & $18,74 \mathrm{~b}$ & $16,02 \mathrm{a}$ & $13,29 \mathrm{~b}$ & $7,44 \mathrm{~b}$ \\
\hline \multicolumn{7}{c}{ CV: } & \multicolumn{7}{c}{$\mathbf{7 , 7 0}$} \\
\hline \multicolumn{7}{c}{ NRC (unid./planta) } \\
\hline Sergipana & $3,29 \mathrm{a}$ & $3,66 \mathrm{a}$ & $2,65 \mathrm{a}$ & $2,57 \mathrm{a}$ & $3,08 \mathrm{a}$ & $3,20 \mathrm{a}$ & $3,41 \mathrm{a}$ \\
Clone 6 & $2,73 \mathrm{ab}$ & $3,03 \mathrm{a}$ & $2,87 \mathrm{a}$ & $3,13 \mathrm{a}$ & $2,67 \mathrm{a}$ & $2,73 \mathrm{ab}$ & $2,73 \mathrm{~b}$ \\
Clone 14 & $2,59 \mathrm{~b}$ & $2,99 \mathrm{a}$ & $2,58 \mathrm{a}$ & $2,67 \mathrm{a}$ & $1,93 \mathrm{~b}$ & $2,29 \mathrm{~b}$ & $2,60 \mathrm{~b}$ \\
\hline CV: & \multicolumn{7}{c}{$\mathbf{1 2 , 5 7}$} \\
\hline \multicolumn{7}{c}{ MMRC $(\mathbf{g})$} \\
\hline Sergipana & $265,0 \mathrm{a}$ & $243,8 \mathrm{a}$ & $223,0 \mathrm{a}$ & $273,3 \mathrm{a}$ & $305,1 \mathrm{a}$ & $235,5 \mathrm{a}$ & $242,9 \mathrm{a}$ \\
Clone 6 & $251,9 \mathrm{a}$ & $212,2 \mathrm{a}$ & $217,3 \mathrm{a}$ & $218,2 \mathrm{ab}$ & $228,4 \mathrm{~b}$ & $232,1 \mathrm{a}$ & $167,8 \mathrm{~b}$ \\
Clone 14 & $245,0 \mathrm{a}$ & $258,7 \mathrm{a}$ & $227,9 \mathrm{a}$ & $189,7 \mathrm{~b}$ & $154,1 \mathrm{c}$ & $238,4 \mathrm{a}$ & $192,7 \mathrm{ab}$ \\
\hline CV: & \multicolumn{7}{c}{$\mathbf{1 3 , 0 0}$} \\
\hline
\end{tabular}

1_/ Médias seguidas da mesma letra nas colunas dentro de cada variável não diferem entre si pelo teste de Tukey ao nível de $5 \%$ de probabilidade.

Quanto ao número das raízes comerciais (NRC), a variedade Sergipana, obteve maior número de raízes tuberosas nos tratamentos com o controle das plantas daninhas durante todo o ciclo, com controle a partir dos 40 e 50 DAP, porém não diferindo estatisticamente Cultura Agronômica, Ilha Solteira, v.26, n.4, p.640-656, 2017 
do Clone 6; e com controle a partir dos 60 DAP, diferindo dos demais genótipos; com o controle das plantas daninhas iniciado a partir dos 10, 20 e 30 DAP, não foi verificado diferença significativa entre os três genótipos de batata-doce.

A massa média das raízes comerciais (MMRC), para os tratamentos onde os genótipos de batata-doce se desenvolveram sobre o controle das plantas daninhas, durante todo o ciclo, a partir dos 10, 20, e 50 DAP, não foi verificada diferença significativa entre os genótipos; já com o controle iniciado a partir dos 30 DAP, a variedade Sergipana, foi superior, porém não diferiu do Clone 6; também foi superior com o controle a partir dos $60 \mathrm{DAP}$, desta vez, não diferindo do Clone 14; já com o controle iniciado a partir dos 40 DAP, a variedade Sergipana mais uma vez foi superior, diferindo significativamente dos demais genótipos.

\section{Avaliação dos caracteres relacionados às raízes tuberosas dos genótipos de batata- doce, em função dos períodos de convivência com as plantas daninhas}

Analisando o desdobramento de genótipos dentro dos períodos de convivência de plantas daninhas, verificou-se para o rendimento de raízes comerciais (RRC), que quando os genótipos de batata-doce permaneceram durante todo o seu ciclo de cultivo em competição com as plantas daninhas, o Clone 6 e a variedade Sergipana não diferiram entre si, apresentando rendimentos de 10,93 e 9,28 $\mathrm{t} \mathrm{ha}^{-1}$, respectivamente, que por sua vez diferiram estatisticamente do Clone 14, que obteve rendimento de 5,98 t ha-1. Nos demais tratamentos a variedade Sergipana obteve maiores rendimentos, no entanto não diferiu estatisticamente do Clone 6 (Tabela 2).

Tabela 2. Valores médios do rendimento de raízes comerciais (RRC), número de raízes comerciais por planta (NRC) e massa média das raízes comerciais (MMRC), dos genótipos de batata-doce em função dos períodos de convivência com as plantas daninhas. Rio LargoAL, CECA-UFAL, 2013.

\begin{tabular}{|c|c|c|c|c|c|c|c|}
\hline \multirow[t]{2}{*}{ Genótipos } & \multicolumn{7}{|c|}{ Períodos de Convivência (DAP) } \\
\hline & 130 & 10-130 & $20-130$ & $30-130$ & $40-130$ & 50-130 & 60-130 \\
\hline & \multicolumn{7}{|c|}{ RRC (t.ha-1) } \\
\hline Sergipana & $9,28 \mathrm{a}$ & $15,13 \mathrm{a}$ & $20,19 \mathrm{a}$ & $23,34 \mathrm{a}$ & $25,49 \mathrm{a}$ & $26,33 \mathrm{a}$ & $26,15 \mathrm{a}$ \\
\hline Clone 6 & $10,93 \mathrm{a}$ & $13,71 \mathrm{a}$ & $18,19 \mathrm{a}$ & $21,66 \mathrm{a}$ & $25,04 \mathrm{a}$ & $25,27 \mathrm{a}$ & $25,47 \mathrm{a}$ \\
\hline Clone 14 & $5,98 \mathrm{~b}$ & $10,46 \mathrm{~b}$ & $14,78 \mathrm{~b}$ & $16,36 \mathrm{~b}$ & $19,12 \mathrm{~b}$ & $21,24 \mathrm{~b}$ & $22,03 \mathrm{~b}$ \\
\hline \multirow[t]{2}{*}{ CV: } & \multicolumn{7}{|c|}{$\mathbf{7 , 7 0}$} \\
\hline & & \multicolumn{6}{|c|}{ NRC (unid. por planta) } \\
\hline Sergipana & $1,39 \mathrm{~b}$ & $2,65 \mathrm{a}$ & $2,78 \mathrm{a}$ & $3,01 \mathrm{a}$ & $3,17 \mathrm{a}$ & $2,36 \mathrm{~b}$ & $3,24 \mathrm{a}$ \\
\hline Clone 6 & $2,13 \mathrm{a}$ & $2,80 \mathrm{a}$ & $2,90 \mathrm{a}$ & $2,95 \mathrm{a}$ & $3,63 \mathrm{a}$ & $3,17 \mathrm{a}$ & $3,33 \mathrm{a}$ \\
\hline Clone 14 & $1,05 \mathrm{~b}$ & $2,60 \mathrm{a}$ & $2,55 \mathrm{a}$ & $2,43 \mathrm{a}$ & $2,46 \mathrm{~b}$ & $2,99 \mathrm{ab}$ & $2,68 \mathrm{a}$ \\
\hline CV: & \multicolumn{7}{|c|}{12,57} \\
\hline & \multicolumn{7}{|c|}{$\operatorname{MMRC~(g)~}$} \\
\hline Sergipana & $161,6 \mathrm{a}$ & $264,8 \mathrm{a}$ & $253,6 \mathrm{a}$ & $256,3 \mathrm{a}$ & $251,5 \mathrm{a}$ & $235,0 \mathrm{a}$ & $215,4 \mathrm{a}$ \\
\hline Clone 6 & $170,5 \mathrm{a}$ & $218,2 \mathrm{ab}$ & $202,7 \mathrm{a}$ & $225,4 \mathrm{a}$ & $239,4 \mathrm{a}$ & $246,7 \mathrm{a}$ & $243,9 \mathrm{a}$ \\
\hline Clone 14 & $167,6 \mathrm{a}$ & $167,9 \mathrm{~b}$ & $204,9 \mathrm{a}$ & $216,9 \mathrm{a}$ & $223,9 \mathrm{a}$ & $261,6 \mathrm{a}$ & $209,2 \mathrm{a}$ \\
\hline CV: & \multicolumn{7}{|c|}{13,00} \\
\hline
\end{tabular}

Cultura Agronômica, Ilha Solteira, v.26, n.4, p.640-656, 2017 


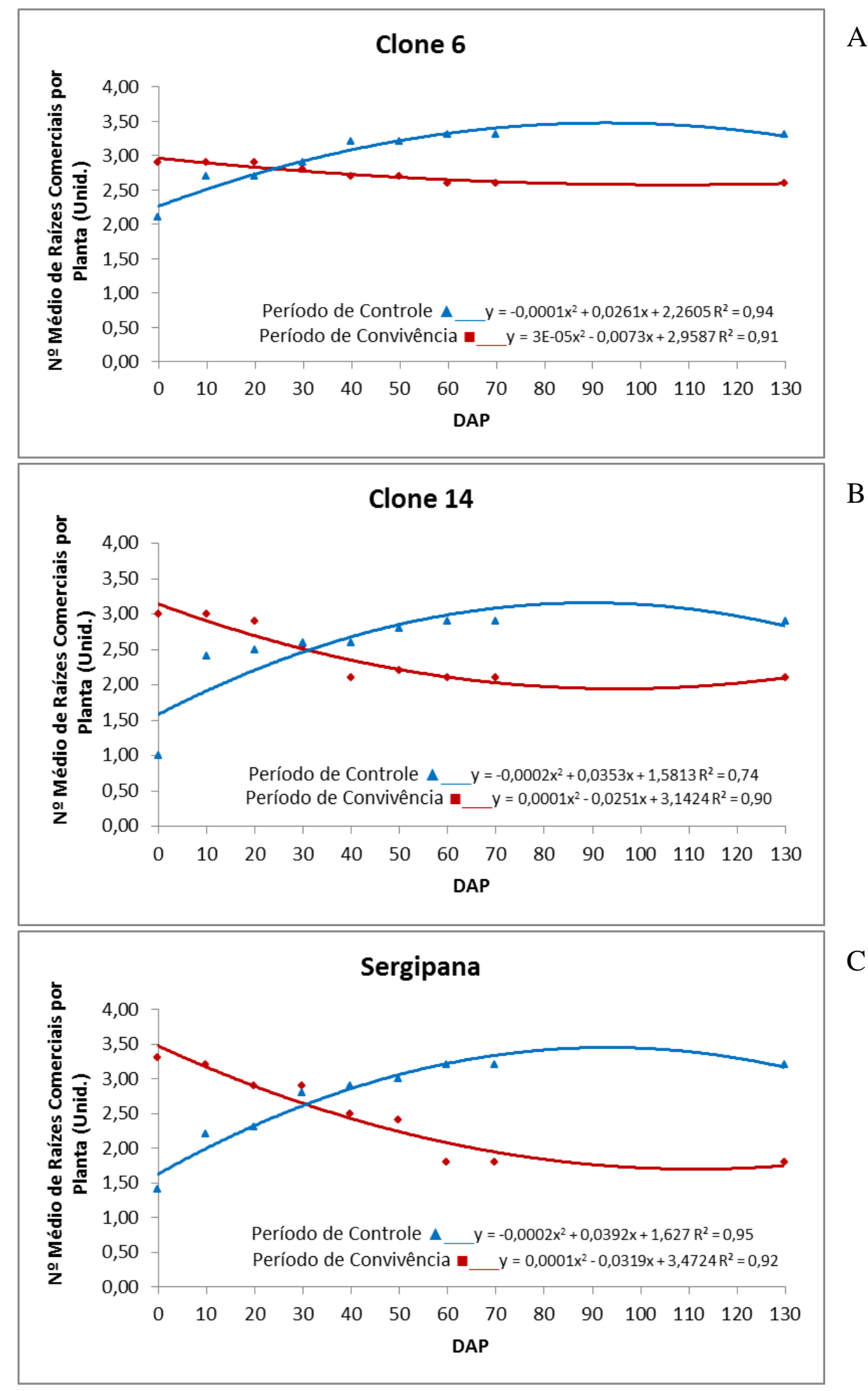

Figura 4. Número de raízes comerciais de batata-doce por planta em função dos períodos de controle e convivência de plantas daninhas no Clone 6 (A), Clone 14 (B) e variedade Sergipana (C). Rio Largo-AL, CECA/UFAL, 2013.

Para o número das raízes comerciais (NRC), no tratamento em convívio com as plantas daninhas, o Clone 6 apresentou o maior número de raízes tuberosas por planta;

Cultura Agronômica, Ilha Solteira, v.26, n.4, p.640-656, 2017 
também foi superior nos tratamentos com controle até os 40 DAP, porém, não diferiu da variedade sergipana; o Clone 6, no tratamento com controle das plantas daninhas até os 50 DAP, mais uma vez foi superior, porém não diferindo do Clone 14; e nos demais tratamentos, não houve diferença significativa entre eles.

Na massa média das raízes comerciais (MMRC), onde o controle das plantas daninhas foi realizado até os 10 DAP, a variedade Sergipana apresentou o maior valor, porém não diferiu significativamente do Clone 6; já para os demais tratamentos, não houve diferença significativa entre os genótipos de batata-doce.

Os estudos relacionados aos caracteres da cultura da batata-doce demonstraram que os períodos de controle e convivência das plantas daninhas apresentaram resultados diversos, para os três genótipos avaliados:

$\mathrm{O}$ número de raízes comerciais por planta (NRC) diminuiu à medida que a cultura aumentou o período de convívio com as plantas daninhas, acontecendo o inverso, à medida que se prolongou o período de controle (Figura $4 \mathrm{~A}, \mathrm{~B}$ e C).

A redução do NRC, para os tratamentos em convivência, durante todo o ciclo, em comparação com os mantidos no limpo, foi de 27,6; 57,6 e 66,67\% para o Clone 6, a variedade Sergipana e o Clone 14, respectivamente, sendo o Clone 6 o menos prejudicado. A depender da infestação de plantas daninhas esse resultado pode chegar a 100\%, como na pesquisa de Albuquerque et al. (2012) na cultura da mandioca, comparando o tratamento na ausência e com a presença de plantas daninhas durante todo o ciclo da cultura, obtiveram redução em $100 \%$ no número de raízes por planta.

A maior massa média de raízes comerciais (MMRC), dos genótipos de batata-doce ocorreu na variedade Sergipana, já entre os Clones 6 e 14 os resultados foram semelhantes, quando mantidos em menores períodos de convivência e em maiores períodos de controle das plantas daninhas (Figura 5 A, B e C).

A MMRC apresentou tendência de crescimento linear com o aumento do período de controle das plantas daninhas e decresceu à medida que a cultura conviveu por maior tempo com as plantas infestantes para todos os genótipos de batata-doce estudados.

A redução da massa média de raízes comerciais dos genótipos de batata-doce no tratamento em convivência com as plantas daninhas, durante todo o ciclo, em comparação com os métodos no limpo, foi de 32,5, 36,0 e 48,1\% no Clone 6, Clone 14 e variedade Sergipana, respectivamente, sendo a variedade Sergipana, a mais afetada pela interferência das plantas daninhas. 


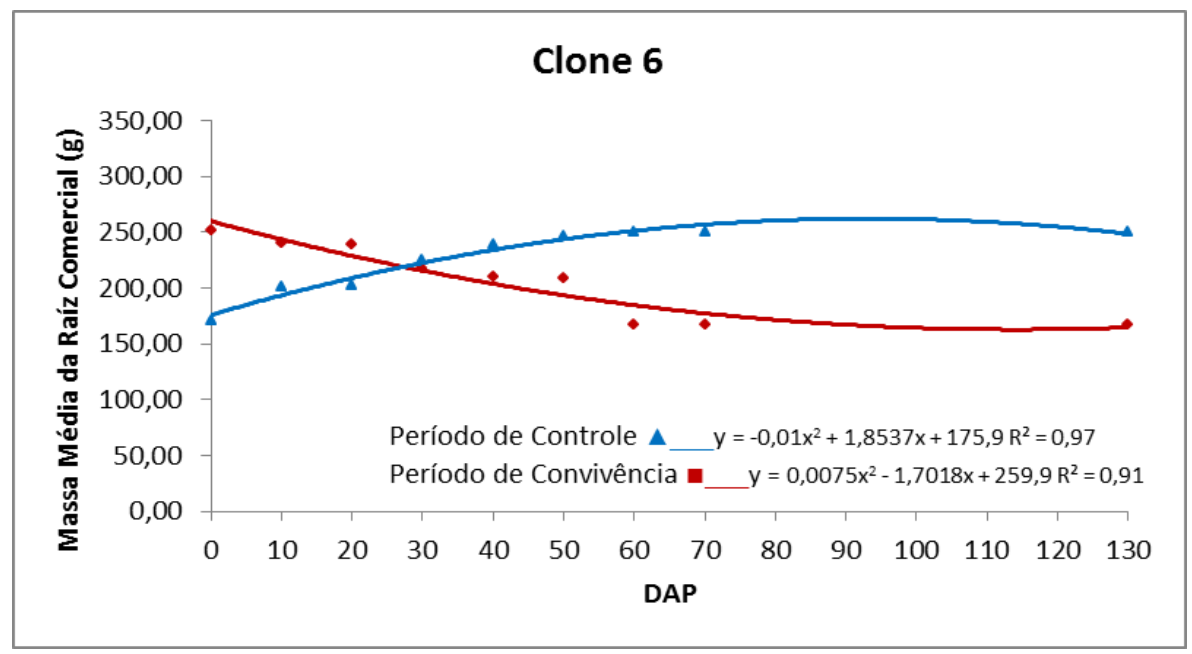

A
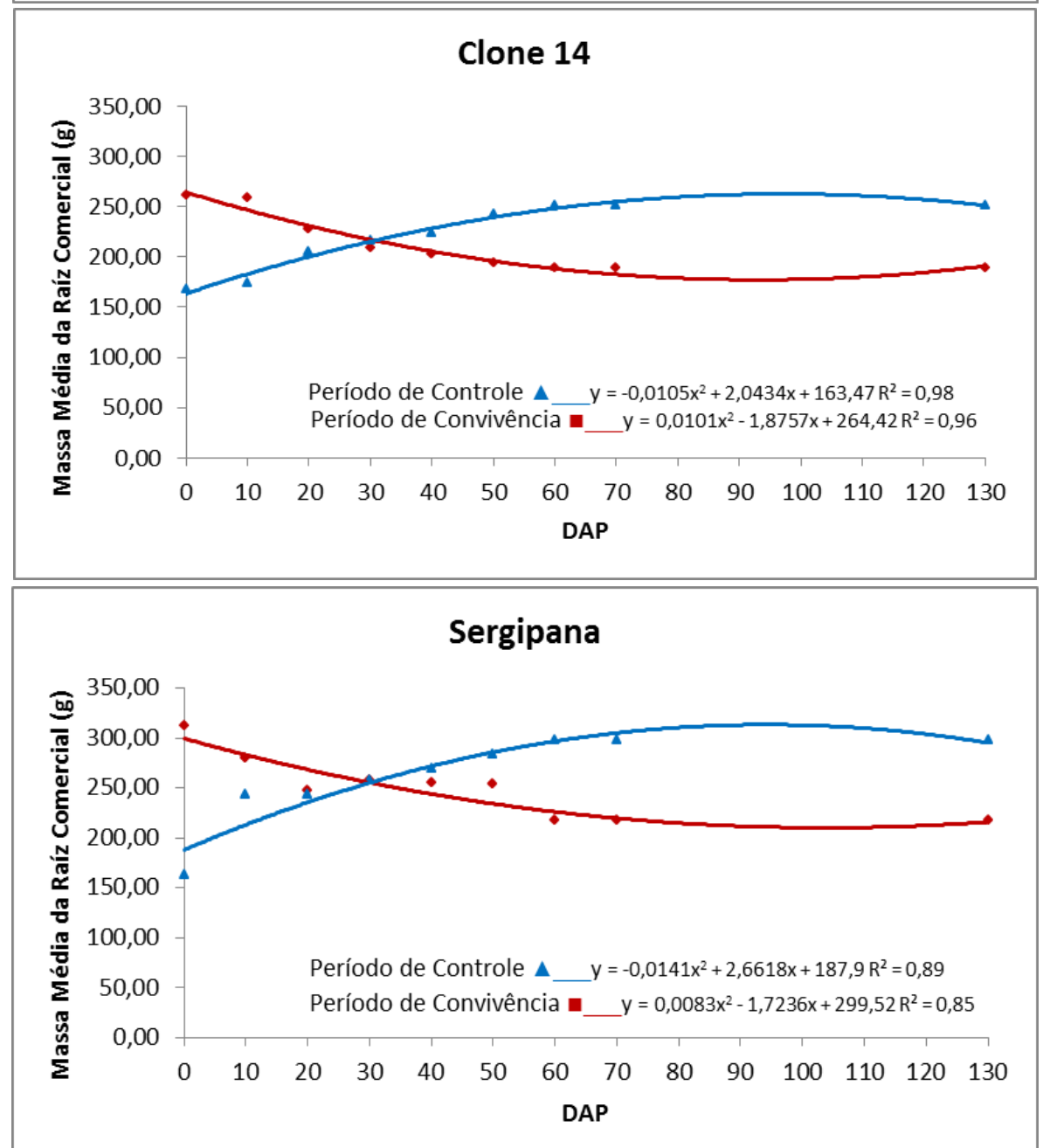

$\mathrm{C}$

Figura 5. Massa média das raízes tuberosas de batata-doce em função dos períodos de controle e convivência de plantas daninhas no Clone 6 (A), Clone 14 (B) e variedade Sergipana (C). Rio Largo-AL, CECA/UFAL, 2013.

$\mathrm{E}$, por fim, analisando o rendimento de raízes comerciais (RRC) dos genótipos de batata-doce, nos períodos de controle e convivência com as plantas daninhas (Figura 6 A, B, 
e C), observa-se que o período anterior à interferência (PAI), que é o momento em que a produtividade das raízes tuberosas passa a ser afetada negativamente pela convivência com as plantas daninhas, no qual deve ser iniciado o controle das plantas infestantes, sem prejuízo econômico, considerando como perda valores a partir de 5\%, dos genótipos analisados, foram os seguintes: Clone 14 aos 17 DAP, variedade Sergipana aos 23 DAP e o Clone 6 aos 24 DAP. Ao se definir o PAI verifica-se que neste período a cultura encontra-se no início do desenvolvimento vegetativo. No entanto, mesmo neste período inicial, observase que já se instalou o processo de interferência das plantas daninhas sobre os genótipos de batata-doce. Um dos principais fatores da interferência está associado à competição pelos recursos do meio. O PAI encontrado de 17 DAP para o Clone 14, teve valor inferior em relação à variedade Sergipana com 23 DAP e o Clone 6 com 24 DAP. Entretanto, o PAI mais curto verificado nesta pesquisa, no Clone 14 (17 DAP), pode ser atribuído, à grande infestação de plantas daninhas na área e à agressividade de algumas espécies que acumularam grande quantidade de massa seca, especialmente a Richardia grandiflora Cham. \& Schltdl. (poaia branca), com 232 plantas $\mathrm{m}^{-2}$ e o Ageratum conyzoides L. (mentrasto), com 210 plantas $\mathrm{m}^{-2}$ aos 20 DAP como consta na Figura 2.

Resultados encontrados por Soares et al. (2010) revelam que os fluxos iniciais de germinação das plantas daninhas, ocorrido logo após a semeadura ou plantio da cultura, são normalmente os de maior intensidade e densidade e muito importantes em termos da interferência inicial, uma vez que impõem à cultura uma situação de restrição de recursos prematuramente, por isso, toda cultura que favoreça a cobertura do solo ou uso de herbicidas de curto período residual acarreta ao final do ciclo menores perdas produtivas.

O período que compreende a época em que a cultura deve ser mantida sem a interferência das plantas daninhas, denominado de Período Total de Prevenção a Interferência (PTPI), foi de 40, 42 e 46 DAP, para o Clone 14, variedade Sergipana e Clone 6 , respectivamente. A partir do final deste período não compensaria, economicamente, o uso de algum método de controle dessas plantas daninhas (BIFFE, 2008). Estudos realizados por Teófilo et al. (2009) indicam que a partir desse momento as plantas daninhas que emergem não interferem mais na produtividade da cultura, devido ao intenso crescimento vegetativo, proporcionando alto índice de área foliar da cultura. 


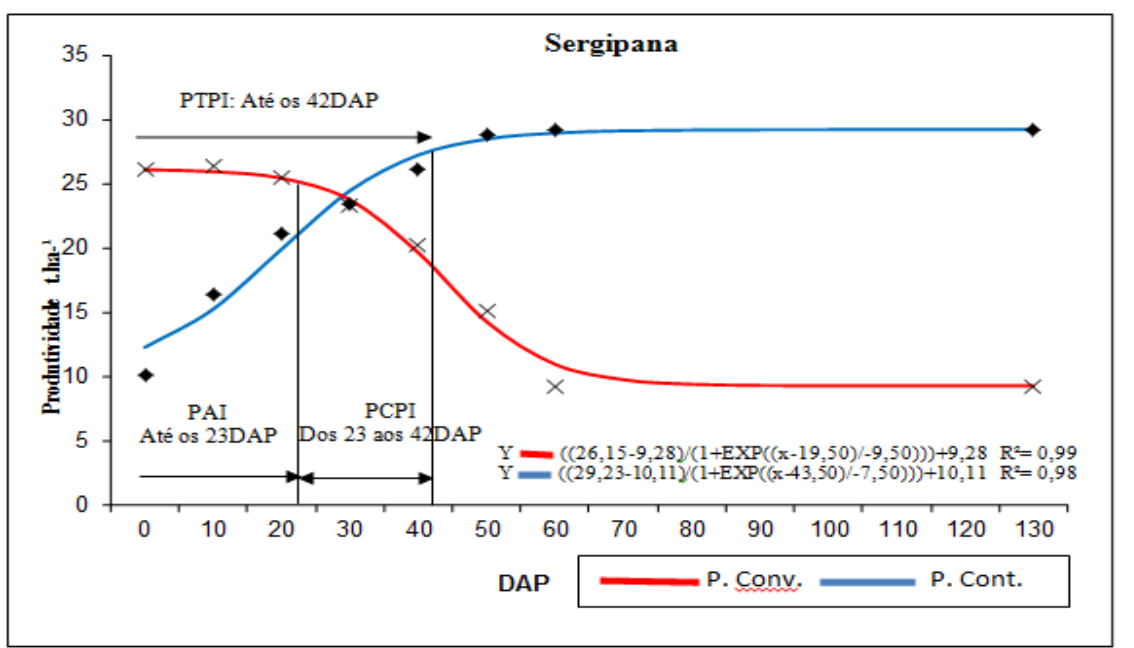

A
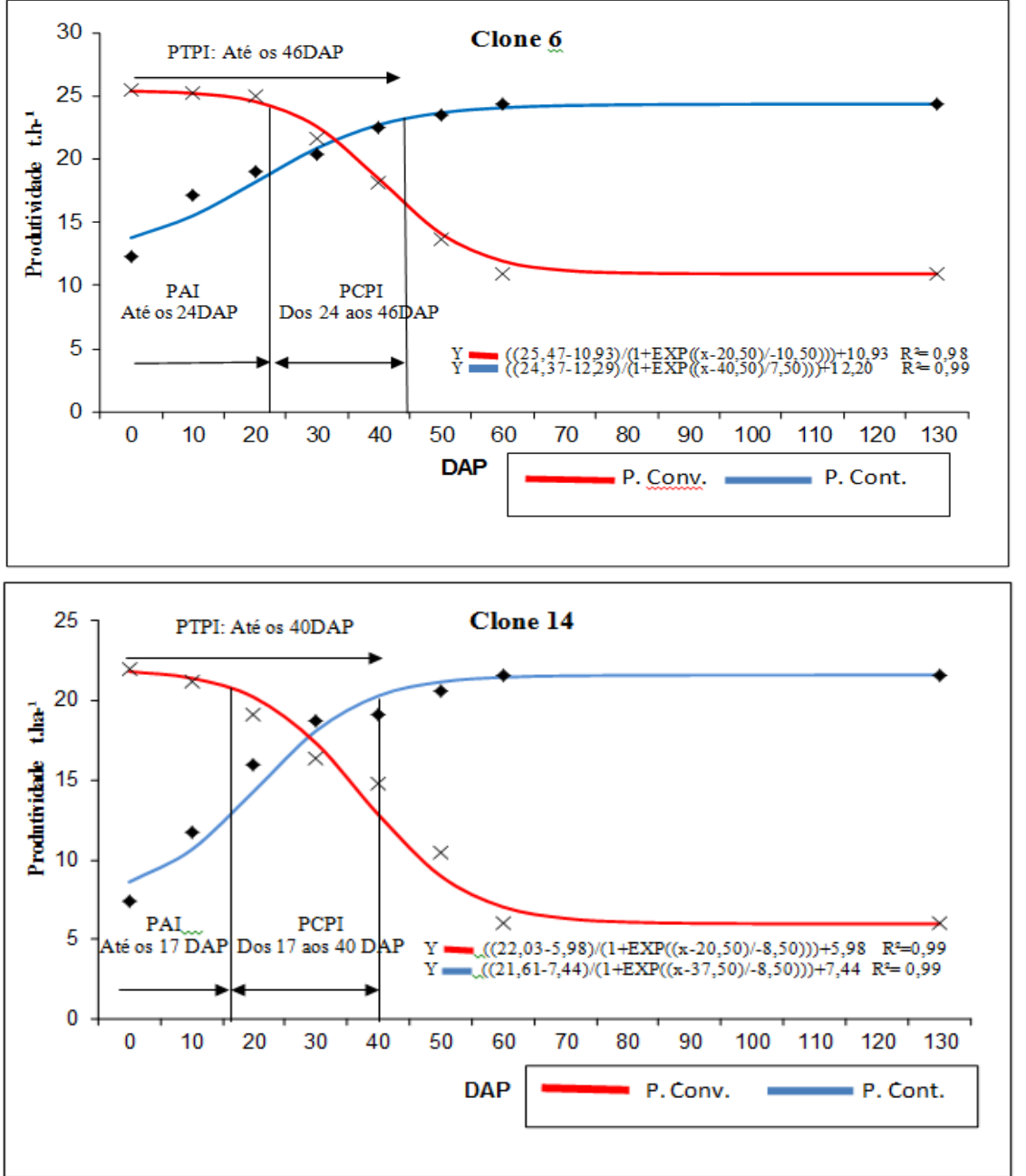

$\mathrm{C}$

Figura 6. Produtividade dos genótipos de batata-doce em função dos períodos de controle (P. Cont.) e convivência (P. Conv.) com as plantas daninhas para a variedade Sergipana (A), Clone $6(\mathrm{~B})$ e Clone $14(\mathrm{C})$, com os respectivos períodos anteriores à interferência (PAI), totais de prevenção à interferência (PTPI) e críticos de prevenção à interferência (PCPI). Rio Largo - AL, CECA-UFAL, 2013.

Cultura Agronômica, Ilha Solteira, v.26, n.4, p.640-656, 2017 
Outros trabalhos evidenciam que a cultura deve ser mantida livre da competição imposta pelas plantas daninhas nos primeiros 45 dias, pois, segundo Silva e Lopes (1995), é a época de maior competição por água, luz, nutrientes e espaço físico entre a cultura e as plantas daninhas. Por outro lado, Filgueira (2008) informa que a batata-doce deve ser mantida livre das plantas daninhas nos primeiros 60 dias. Seguindo o mesmo pensamento, Cardi (2010) confirma que período crítico para o controle das plantas daninhas em batatadoce é durante os primeiros dois meses de crescimento. Após esse período, o crescimento das ramas deve efetivamente cobrir a superfície do solo, suprimindo assim as plantas daninhas. De acordo com Seem et al. (2003), estudando o PTPI, a interferência foi de 42 DAP. Semidey et al. (1987), também avaliando a interferência de plantas daninhas na cultura da batata-doce, obtiveram um PTPI de 28 DAP.

$\mathrm{O}$ período crítico de prevenção à interferência (PCPI), intervalo compreendido entre o PAI e o PTPI, foi de 17 aos 40 DAP, para o Clone 14; de 23 aos 42 DAP para a variedade Sergipana; e de 24 aos 46 DAP para o Clone 6 (Figura 6 A, B e C).

De acordo com Soares et al. (2010) e Freitas et al. (2009), o PCPI é o período em que a cultura deve ser mantida livre da interferência das plantas daninhas. A variedade Sergipana reduziu em 4 dias a necessidade de capinas em comparação com o Clone 14 e em 3 dias em relação ao Clone 6.

Segundo Seem et al. (2003), estudando a interferência das plantas daninhas Amaranthus retroflexus (bredo), Senna obtusifolia (mata-pasto) e Cyperus esculentus (tiririca) na cultura da batata-doce, na Carolina do Norte - USA, observaram que o PCPI variou de 14 a 42 dias após o plantio (28 dias). Contudo, Levett (1992), encontrou o PCPI de plantas daninhas na cultura da batata-doce, cultivares "L11", "L44" e E L431" dos 7 aos 56 dias após o plantio (49 dias).

\section{CONCLUSÃO}

Dessa forma, considerando a perda de $5 \%$ na produtividade como aceitável, foi possível determinar:

O período anterior à interferência (PAI), de 17 DAP para o Clone 14, de 23 DAP para a variedade Sergipana e de 24 DAP para o Clone 6;

O período total de prevenção à interferência (PTPI), de 42, 46 e 40 DAP, respectivamente, para a variedade Sergipana, Clone 6 e o Clone 14;

E o período crítico de prevenção da interferência (PCPI), período em que os genótipos de batata-doce devem ser mantidos livres de competição com as plantas daninhas, que se dá entre 23 e 42 DAP, para a variedade Sergipana, 24 e 46 DAP, para o Clone 6, e entre 17 e 40 DAP, para o Clone 14.

O efeito da interação da competição entre a comunidade de plantas daninhas e os genótipos de batata-doce, podem apresentar-se extremamente variável. Essa interação está 
correlacionada com as espécies de plantas daninhas presentes na comunidade infestante, com os genótipos de batata-doce e também com as características do meio.

Esses dados são de importância relevante para a determinação de estratégias de manejo das plantas daninhas, indicando o intervalo de tempo quando o controle poderá ser mais efetivo na prevenção de danos a cultura da batata-doce. Constata-se, no entanto, a necessidade da realização de mais estudos, pois os trabalhos desenvolvidos até o momento estão restritos a algumas espécies, havendo carência de informações para a cultura em estudo.

\section{REFERÊNCIAS BIBLIOGRÁFICAS}

AlbuQuerque, J. A. A.; SEDIYAMA, T.; SilvA, A. A.; AlVES, J. M. A.; FINOTO, E. L.; NETO, F. A.; SILVA, G. R. Desenvolvimento da cultura de mandioca sob interferência de plantas daninhas. Planta daninha, Viçosa, v. 30, n. 1, p.37-44, 2012.

BIFFE, D. F. Período crítico de interferência de plantas daninhas e seletividade de herbicidas para a cultura da mandioca na região noroeste do Paraná. 2008. 48 f. Dissertação (Mestrado em Agronomia) - Universidade Estadual de Maringá, Maringá-PR.

CARDI - CARIBBEAN AGRICULTURAL RESEARCH AND DEVELOPMENT INSTITUTE. Sweet Potato Technical Manual. St Augustine: CARDI, 2010. 56 p.

CARDOSO, A. D.; VIANA, A. E. S.; BARBOSA, R. P.; TEIXEIRA, P. R. G.; CARDOSO JÚNIOR, N. S.; FOGAÇA, J. J. N. L. Levantamento fitossociológico de plantas daninhas na cultura da mandioca em Vitória da Conquista, Bahia. Bioscience Journal, Uberlândia, v. 29, n. 5, p.1130-1140, 2013.

COELHO, M.; BIANCO, S.; CARVALHO, L. B. Interferência de plantas daninhas na cultura da cenoura (Daucus carota). Planta daninha, Viçosa, v. 27, n. especial, p.913920, 2009.

COSTA, N. V.; CARDoso, L. A.; RODRIGUES, A. C. P.; MARTINS, D. Períodos de interferência de uma comunidade de plantas daninhas na cultura da batata. Planta daninha, Viçosa, v. 26, n. 1, p.83-91, 2008.

COSTA, N. V.; RITTER, L.; PERES, E. J. L.; SILVA, P. V.; VASCONCELOS, E. S. Weed interference periods in the "fécula branca" cassava. Planta Daninha, Viçosa, v. 31, n. 3, p.533-542, 2013.

CUNHA, J. X. L.; FREITAS, F. C. L.; COELHO, M. E. H.; SILVA, M. G. O.; MESQUITA, H. C.; SILVA, K. S. Período de interferência de plantas daninhas na cultura do pimentão nos sistemas de plantio direto e convencional. Revista Agro@mbiente, Boa Vista, v. 9, n. 2, p.175-183, 2015.

Cultura Agronômica, Ilha Solteira, v.26, n.4, p.640-656, 2017 
EMBRAPA - EMPRESA BRASILEIRA DE PESQUISA AGROPECUÁRIA. Manual de Métodos de Análise de solo. 2. ed. Rio de Janeiro: Embrapa Solos, 2011. 225 p. (Documentos 132).

FAO - FOOD AND AGRICULTURE ORGANIZATION OF THE UNITED NATIONS. Data Crops: Sweet potatoes. 2014. Disponível em: http://www.fao.org/faostat/en/\#data/QC/visualize . Acesso em: 10 jun. 2017.

FILGUEIRA, F. A. R. Novo manual de olericultura: agrotecnologia moderna na produção e comercialização de hortaliças. 3. ed. Viçosa: Editora UFV, 2008. 442 p.

FREITAS, R. S.; SEDIYAMA, M. A. N.; PEREIRA, P. C.; FERREIRA, F. A.; CECON, P. R.; SEDIYAMA, T. Períodos de interferência de plantas daninhas na cultura da mandioquinha-salsa, Planta daninha, Viçosa, v. 22, n. 4, p.499-506, 2004.

FREITAS, F. C. L.; ALMEIDA, M. E. L.; NEGREIROS, M. Z.; HONORATO, A. R. F.; MESQUITA, H. C.; SILVA, S. V. O. F. Períodos de interferência de plantas daninhas na cultura da cenoura em função do espaçamento entre fileiras. Planta daninha, Viçosa, v. 27, n. 3, p.473-480, 2009.

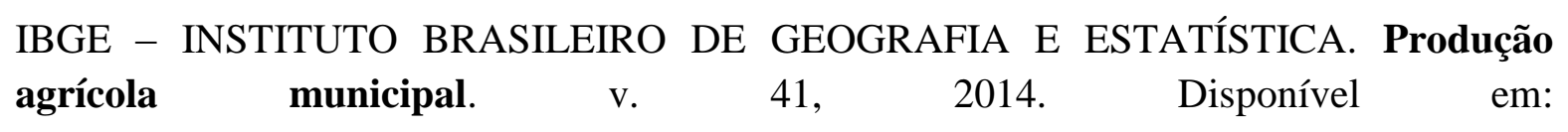
ftp://ftp.ibge.gov.br/Producao_Agricola/Producao_Agricola_Municipal_ [anual]/2013/tabelas.pdf/tabela02.pdf . Acesso em: 03 fev. 2015.

KUVA, M. A.; GRAVENA, R. A.; PITELli, R. A.; CHRISTOFFOLETI, P. J.; ALVES, P. L. C. A. Períodos de interferência das plantas daninhas na cultura da cana-de-açúcar. III capim-braquiária (Brachiaria decumbens) e capim-colonião (Panicum maximum). Planta Daninha, Viçosa, v. 21, n. 1, p.37-44, 2003.

LEVETT, M. P. Effects of varius hand-weeding programmes on yield and componentes of yield of sweet potato (Ipomoea batatas) grown in the tropical lowlands of Papua New Guinea. Journal Agricultural Science, Cambridge, v. 118, n. 1, p.63-70, 1992.

MUELLER-DOMBOIS, D.; ELLEMBERG, H. Aims and methods of vegetation ecology. New York: John Willey \& Sons, 1974. 547 p.

NEPOMUCENO, M.; ALVES, P. L. C. A.; DIAS, T. C. S.; PAVANI, M. C. M. D. Períodos de interferência das plantas daninhas na cultura da soja nos sistemas de semeadura direta e convencional. Planta daninha, Viçosa, v. 25, n. 1, p.43-50, 2007.

SEEM, J. E.; CREAMER, N. G.; MONKS, D. W. Critical weed-free period for 'Beauregard' sweetpotato (Ipomoea batatas). Weed Technology, Champaign, v. 17, n. 4, p.686-695, 2003.

SEMIDEY, N.; LIU, L. C.; ORTIZ, F. H. Competition of pigweed (Amaranthus dubius) with sweetpotato (Ipomoea batatas). Journal of Agriculture, University of Puerto Rico, v. 71, n. 1, p.7-11, 1987.

Cultura Agronômica, Ilha Solteira, v.26, n.4, p.640-656, 2017 
SILVA, A, A.; SILVA, J. F. Tópicos em Manejo de plantas daninhas. 1. ed. Viçosa: Editora UFV, 2009. 367 p.

SILVA, J. B. C.; LOPES, C. A. Cultivo da batata-doce. 3. ed. Brasília: EMBRAPA, 1995. 18 p. (Instruções Técnicas de CNPHortaliças - 7).

SOARES, I. A. A; FREITAS, F. C. L.; NEGREIROS, M. Z.; FREIRE, G. M.; AROUCHA, E. M.; GRANGEIRO, L. C.; LOPES, W. A. R.; DOMBROSKI, J. L. D. Interferência das plantas daninhas sobre a produtividade e qualidade de cenoura. Planta Daninha, Viçosa, v. 28, n. 2, p.247-254, 2010.

TEÓFILO, T. M. S.; FREITAS, F. C. L.; NEGREIROS, M. Z.; LOPES, W. A. R.; VIEIRA, S. S. Crescimento de cultivares de cenoura nas condições de Mossoró-RN. Revista Caatinga, Mossoró, v. 22, n. 1, p.168-174, 2009. 